\title{
Open source tools for geographic analysis in transport planning
}

\author{
Robin Lovelace ${ }^{1}$ (D)
}

Received: 3 September 2019 / Accepted: 12 November 2020 / Published online: 16 January 2021 (c) The Author(s) 2021

\begin{abstract}
Geographic analysis has long supported transport plans that are appropriate to local contexts. Many incumbent 'tools of the trade' are proprietary and were developed to support growth in motor traffic, limiting their utility for transport planners who have been tasked with twenty-first century objectives such as enabling citizen participation, reducing pollution, and increasing levels of physical activity by getting more people walking and cycling. Geographic techniques-such as route analysis, network editing, localised impact assessment and interactive map visualisationhave great potential to support modern transport planning priorities. The aim of this paper is to explore emerging open source tools for geographic analysis in transport planning, with reference to the literature and a review of open source tools that are already being used. A key finding is that a growing number of options exist, challenging the current landscape of proprietary tools. These can be classified as command-line interface, graphical user interface or web-based user interface tools and by the framework in which they were implemented, with numerous tools released as $\mathrm{R}$, Python and JavaScript packages, and QGIS plugins. The review found a diverse and rapidly evolving 'ecosystem' tools, with 25 tools that were designed for geographic analysis to support transport planning outlined in terms of their popularity and functionality based on online documentation. They ranged in size from single-purpose tools such as the QGIS plugin AwaP to sophisticated stand-alone multi-modal traffic simulation software such as MATSim, SUMO and Veins. Building on their ability to re-use the most effective components from other open source projects, developers of open source transport planning tools can avoid 'reinventing the wheel' and focus on innovation, the 'gamified' A/B Street https:/github.com/ dabreegster/abstreet/\#abstreet simulation software, based on OpenStreetMap, a case in point. The paper, the source code of which can be found at https:/github.com/ robinlovelace/open-gat, concludes that, although many of the tools reviewed are still evolving and further research is needed to understand their relative strengths and barriers to uptake, open source tools for geographic analysis in transport planning
\end{abstract}

Robin Lovelace

R.Lovelace@leeds.ac.uk

1 University of Leeds Institute for Transport Studies, Leeds, UK 
already hold great potential to help generate the strategic visions of change and evidence that is needed by transport planners in the twenty-first century.

Keywords Open source · Geographic data · Transport planning · Software · Transport modelling · Geographic data analysis

JEL Classification R41 · C6

\section{Introduction: geographic analysis in transport planning}

Transport planning is an applied discipline involving developing local policies and the design and placement of physical infrastructure including ways-highways, railways, cycleways and footways - for the greatest economic, social and environmental benefit (O'Flaherty and Bell 1997; Parkin 2018). Planning also involves thinking about the future, envisioning scenarios of change and making the case for change (Timms et al. 2014). Successful transport plans are therefore a combination of geographically specific recommendations (e.g. "build this way here") and long-term strategies guided by citywide, regional and national visions (e.g. "imagine the benefits of making the city free from private cars by 2030"). The rewards can be great: transport planners who have designed — and helped to implement—plans appropriate to the needs of an area leave a legacy that will benefit people and the environment for generations to come. ${ }^{1}$

Transport planning can be considered as "more of an art than a technique", although good transport plans also rely on robust analysis and modelling of sometimes large and usually spatial input datasets (de Dios Ort'uzar and Willumsen 2011). Ways and other pieces of transport infrastructure must go somewhere; transport planning involves consideration of where investment and other interventions are most needed. Tools for geographic analysis have been used in transport planning since at least the 1990s, when local transport planning bodies in the United States started using geographic information systems (GIS) software to support their transport planning activities (Anderson 1991), taking advantage of newly available software and hardware such as the Intel 80386 processor (first released in 1985) which could run early proprietary GISs such as 'SPANS' (Ebdon 1992).

Despite the inherently geographic nature of movement, and the growth of GIS in transport planning, the importance of geographic in transport systems has long been overlooked (Rodrigue et al. 2013), notwithstanding efforts to formalise the field of 'GIS-T,' described in the next section. Geographic methods-such as origin-destination modelling, route assessment and spatial network analysis - are prominent in the literature, providing evidence for a range of transport planning interventions (e.g. Jäppinen et al. 2013; Larsen et al. 2013; Tribby and Zandbergen 2012). But there has been less research into digital geographic tools, as discussed in Sect. 3, despite

\footnotetext{
${ }^{1}$ Articles about successful transport planners illustrate the point. Ben Hamilton-Baillie (1955-2019), for example, was an influential transport planner and street designer whose obituary emphasised the "hundreds of thousands of people who are safer and happier as a result of his achievements" (Tim Stornor, quoted in TransportExtra).
} 
the fact that geographic methods must be accompanied by software and a user interface if they are to be of use in practice.

A range of data driven transport planning approaches has evolved in recent years to take advantage of new datasets and technologies. Large movement datasets from disruptive 'ride hailing' firms have been used to better understand parking patterns (Aryandoust et al. 2019); 'deep learning' has been used to forecast demand for transport services in near real-time (Liao et al. 2018). Such novel geographic approaches can be defined as Geographic Data Science, a still emerging field that calls for the tighter integration between data science and geographic research (Singleton and Arribas-Bel 2019). While there is much academic activity in this direction, the extent to which new geographic tools have gained traction in practice, and in transport planning practice in particular, is debatable. In this context, the goal of this paper is to add to the literature on geographic tools in transport planning, with a focus on open source options.

At this point some definitions are in order. Although ubiquitous in the literature, terms such as 'tool', 'software' and 'model' are often used interchangeably, relying on the (potentially unsafe) implicit assumption that everyone shares the same idea of what they mean (see Salter et al. 2009 for an example). For the purposes of this paper, a tool is a broad term referring to a modular piece of software or online service; a model, by contrast, is method or process that is expounded in theoretical terms; software is the collection of computer instructions that underlies digital tools, encoded in publicly available and transparent programming languages (in open source software) or in a 'binary' file that has "limits against usage, distribution, and modification that are imposed by its publisher" (Dhir and Dhir 2017), the inner workings of which are obfuscated from the user (in proprietary software). An increasingly used but seldom defined term in this context is ecosystem which, following Franco-Bedoya et al. (2017), we define as the wider community of people organisations that support the development of open source software. The paper focuses on tools, as opposed to software or software ecosystems, because tools are tangible and widely understood (unlike software ecosystems) entities that the end user sees (as opposed to software, which is a rather esoteric concept).

The focus on open source tools for geographic analysis in transport planning is timely because this is an area of rapid growth, as outlined in Sect. 4. The topic has yet to be explored in the academic literature, to the best of the author's knowledge. A deeper reason that transport planning benefits from levels of transparency and citizen participation that are more easily reached with open source solutions than proprietary solutions (Peters 2020). Transport planning involves decisions about how public funds, spaces and other shared resources are used. It is, to a greater or lesser extent, part of wider democratic processes that reflect contemporary political and societal priorities (Legacy 2016). These priorities have shifted substantially over the past few decades, meaning that transport plans based on out-of-date ideas or faulty model assumptions (such as the assumption that congestion can be tackled by building more roads) can lead to unwanted impacts (such as increased congestion), which can be fatal (Hollander 2016).

The importance of transparency and democratic accountability in transport planning (and hence the importance of open source tools in transport planning) has increased alongside wider campaigns for evidence-based decision making and 'participatory democracy' (Monbiot 2017; Hackl et al. 2019), and growing 
evidence that transport systems cause substantial damage to the environment and human health and wellbeing. Roads are now the "leading cause of death for children and young adults aged 5-29 years" with 1.35 million people killed and tens of millions injured and disabled each year due a range of factors including unsafe speeds, weak road traffic laws, lack of enforcement and poor infrastructure that forces pedestrians and cyclists to mix with motorised modes (World Health Organization 2018). The air pollution impacts could be even greater, with a growing body of research linking air pollution to Alzheimer's disease, lung cancer and heart disease among hundreds of millions of sufferers worldwide (Kampa and Castanas 2008; Kilian and Kitazawa 2018). Transport is responsible for a quarter of global greenhouse gas emissions and growing (Harrison and Hester 2017), and is one of the hardest sectors to decarbonise (Moriarty and Honnery 2008), meaning that reducing transport energy use is an urgent priority.

Transport planning is inherently embedded within local geographic contexts because transport systems, and associated networks of physical infrastructure, are highly localised (Barth'elemy 2011; Levinson 2012) and to some degree dynamic (Xie and Levinson 2011) phenomena. Transport planning is therefore fundamentally a geographic activity. All accurate geographic coordinates are defined with reference to the Earth's surface, either via geographic or projected coordinate systems (Sherman 2008). By extension, transport planning is a geographic enterprise.

The influential textbook Modelling Transport outlines the main stages of transport planning as follows (de Dios Ort'uzar and Willumsen 2011).
(1) problem formulation
(2) data collection
(3) modelling/analysis
(4) evaluation
(5) implementation of solutions

Each of these stages, illustrated in Fig. 1, has geographic components. The third stage, can refer to at least three distinct processes: the 'four stage' transport model (left box); scenario modelling (central box) or geographic analysis and modelling (right box, Fig. 1). The wider point is that geographic techniques can supplement and in some cases replace traditional modelling, and the classic four stage transport model. Many of the inputs (datasets with geographic coordinates) and outputs (maps and geographically specific recommendations) shown in Fig. 1 are spatial, suggesting the importance of geographic tools throughout the transport planning process.

Formulation of the problem (stage 1 in the transport planning process illustrated in Fig. 1) and identification of the scope of solutions that the transport planning process can propose is inherently geographic. The first step of many projects is defining the 'region of interest'. This step has important implications because it can focus the analysis on areas where solutions are most likely to be implemented 


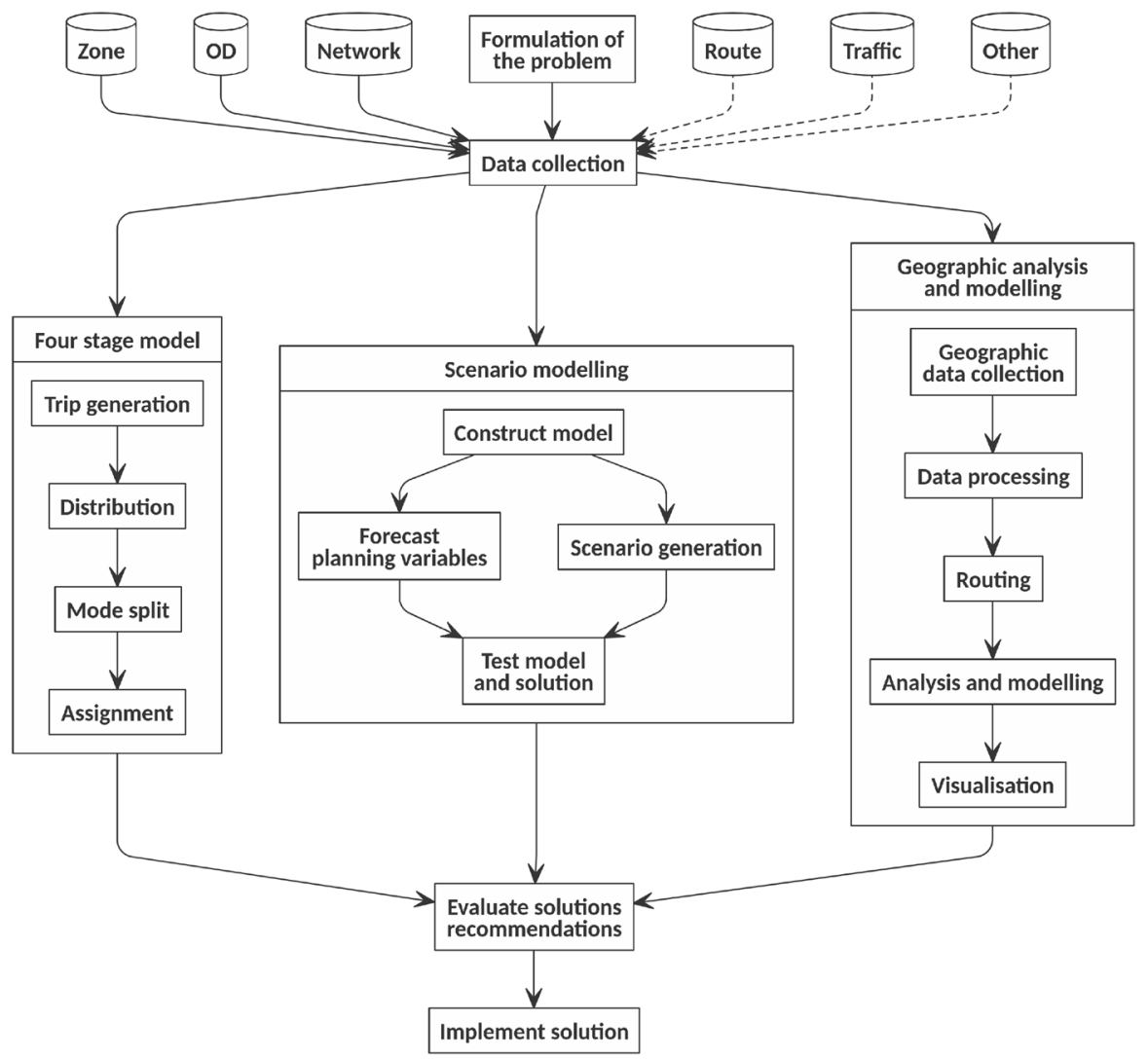

Fig. 1 Schematic diagram illustrating the modelling process, geographic analysis and the four-stage in the context of the wider transport planning process (adapted from de Dios Ort'uzar and Willumsen 2011, with the 'Geographic analysis and modelling component' added for this paper)

and, conversely, highlight the potential for inter-regional collaboration. Although the region of interest may be pre-determined by administrative boundaries over which a planning authority presides, geographic analysis this first stage in the transport planning process can help refine the definition of the 'region of interest' to include different 'spheres of influence' such as the wider catchment area, the administrative region, and the area that is the focus of the study.

Data collection (stage 2) is an explicitly geographical activity, although in some cases the geographic components of valuable data are not used (origin-destination datasets in which the coordinates of origins and destinations are excluded represent a common example). Geographic analysis tools can support this stage not only by providing descriptive overviews of the datasets available to planners (and their limitations such as parts of a city lacking in data), but by flagging places where additional monitoring is needed (e.g Lindsey et al. 2013). 
Likewise, modelling (stage 3) is a central component of data-driven transport planning. Whether the modelling involves a four stage model, statistical modelling or geographic analysis, it inevitably contains some geographic analysis. Geographic analysis is implicit in the classic four-stage model: (1) trip generation (the number of trips generated by each zone in a region) is influenced by geographic factors such as number of buildings in the direct surroundings; (2) the distribution of these trips to destinations depends on explicitly geographic factors such as absolute and relative distances; (3) mode split is influenced by geographic factors such as the gradient and motor traffic speeds and volumes associated with routes between origins and destinations; and (4) assignment to the route network clearly depends on a realistic representation of footways, cycleways, highways and other geographic entities such as traffic lights that affect route choice. Likewise statistical modelling includes consideration of trip distances and destinations, which imply some level of geographic analysis. Four-stage and statistical modelling options can be supplemented by geographic analysis and modelling, something that has been recognised since at least the 1990s (Anderson 1991). Critical to any modelling exercise are scenarios, which can be either 'global' (such as a nationwide increase in fueld tax) or 'local' (such as the creation of new public transport routes on specific roads) in nature. The latter type of scenario require geographical inputs, such as simulating a new cycleway or bus stop. These are arguably more tangible and relevant to the city and regional levels at which many transport plans are developed than abstract 'global' changes (e.g. Larsen et al. 2013).

Geographic considerations are particularly important in stage 4, evaluation of solutions and recommendations to policy makers, but are often overlooked. If recommendations resulting from an 'optimal' model have geographically uneven impacts, it risks exacerbating existing spatial inequalities. Geographic analysis of the results of the transport planning process, in addition to geographic analysis of input data, can support more spatially equitable development which could have a co-benefit of reducing travel demand: wage and other differences between cities are a major driver of (often energy intensive) inter-city travel demand (Schmutz and Sidib'e 2019). And of course the the implementation of effective solutions relies on results that are specific, including being geographically specific and presented in clear and accurate geographic visualisations (Pensa et al. 2013).

The stages represented in Fig. 1 have been criticized for being simplistic, linear and 'top-down', with particularly strong criticisms focusing on the lack of stages for impact assessment and public participation (Löfgren et al. 2018; Tornberg et al. 2018), and more sophisticated representations of key stages in the planning system have been expounded for some time (Batty 1995). However, there is little doubt that the 'formulate $\rightarrow$ collect $\rightarrow$ model $\rightarrow$ evaluate $\rightarrow$ implement' approach continues to be popular and that, within this framework, each stage (particularly 'modelling' which includes geographic analysis and modelling) could benefit from increased access to geographic insights. Due partly to data and computing limitations (outlined in the next section) geographic considerations are not always considered, with consequences for the solutions resulting from the transport planning process and the extent to which they adapt to local geographic factors. Lack of access to, knowledge of and skills in the use of tools for geographic analysis represents another reason 
why geographic factors may be excluded from transport plans (although evidence of the tools that transport planners use and can use is scarce, suggesting areas of future research, as discussed in Sect. 5). There is evidence that these 'barriers to entry' for geographic analysis - at high resolution based on high quality data and high performance software-are being removed, as outlined in Sect. 4. In this context, the aim of this paper is to explore emerging open source tools for geographic analysis in transport planning, with reference to the literature.

The increased availability of open access geographic data and high performance computing technologies (in addition to policy drivers increasing demand for geographic analysis) over the last few decades are discussed in the next section. Despite the increasing availability of open source options, proprietary tools still appear to dominate transport planning in practice, as we will see in Sect. 3. The nature and functionality of open source tools for geographic analysis in transport planning is outlined in Sect. 4. Section 5 concludes by summarising the state and future prospects of open tools in transport planning, highlighting gaps in the current crop of open source options, and flagging ways of getting involved to improve the provision of open source tools for the benefit of researchers, companies, governments and interested citizens with stakes in transport planning processes.

\section{Policy and technological drivers}

Two major drivers of change in transport planning tools have historically been technological development and shifting political priorities (Boyce and Williams 2015). Environmental, health and equality regulations - which can be seen as a manifestation of political change-have also influenced transport planning practice and some specific transport planning tools have emerged to tackle particular issues (e.g. Vandenbulcke et al. 2009). Environmental concerns, including fears about the impact of climate change, have risen up policy agendas in recent years, meaning that such environmental policy drivers a likely to become more important in the coming years. In parallel, the 'obesity crisis' and mounting evidence of the health benefits of physical activity have provided impetus to plans that prioritise walking and cycling, with environmental co-benefits. There have also been calls for more 'bottom-up' and participatory approaches, although transport planning practice has been slow to change in this direction (Legacy 2016). No less important is the demand for localised results; while a national transport model can provide a high level overview of the transport system for policy-makers, tools that provide geographically specific results, potentially down to the street level, can support transport planners 'on the ground.'

Environmental and (local participatory) political factors drive demand for transport planning tools that enable geographic analysis: sustainable modes such as walking and cycling (and to a lesser extent public transport) require greater consideration in the spatial variation in trip origins and destinations at high levels of geographic resolution: analysis with limited consideration of geographic factors, such as the 
spatial distribution of locations within walking distance of new infrastructure, is less able to inform investment in active travel or provide citizens with localised information. A final driver of demand for such tools is technology. Rapidly emerging digital technologies could transform transport planning, with two-way communications between planning authorities and citizens, and even peer-to-peer communications on transport planning issues, now feasible. ${ }^{2}$ These drivers of change provide the context in which open source tools for transport planning are being developed.

\subsection{Political drivers}

The history of transport modelling shows that transport planning software was originally designed in the late 1950s and onwards to plan for "increased use of cars [for personal travel], and trucks for deliveries and goods movement" (Boyce and Williams 2015). Policy drivers have changed dramatically since then: climate change mitigation, air quality improvement and public health are prioritised in the emergent 'sustainable mobility paradigm' (Hickman et al. 2011; Johansson et al. 2017; Department for Transport 2020). Yet many traditional transport planning tools focus on motor traffic, emphasising travel time savings impacts over environmental and health savings (Hall et al. 1980; de Dios Ort'uzar and Willumsen 2011), often at low levels of geographic resolution (Hollander 2016). These observations have led to criticism of transport models which are deemed unable to represent transport network details such as pavement and way widths that are needed effectively designed for active transport (Parkin 2018) or capture community input (Beimborn and Kennedy 1996).

Tools for twenty-first century transport planning need to tackle very different questions, such as: What are the barriers preventing people from switching to more sustainable modes of transport, and where are these barriers located? How are transport behaviours likely to shift in the future, in response to technological changes including autonomous vehicles and the continued rise of online working? Where will different types of intervention be most effective? And how can citizens be engaged in transport decisions? Tools that can help answer these questions are becoming an increasingly important part of the transport planner's cabinet (te Brömmelstroet and Bertolini 2008).

As the gap between what the science seems to say is necessary in the near future and the reality of polluting and unhealthy transport systems grows, so does the need for transparent models that stand up to scrutiny and enable participation and informed debate. This has been well documented in with respect to energy models by Morrison (2018), who observed that "opaque policy models simply engender distrust". The same could be said of transport models, driving demand for tools that are open to public scrutiny and community involvement. In parallel, growing awareness of the need for sustainable transport planning solutions has also driven demand for geographically locallised transport planning tools.

\footnotetext{
${ }^{2}$ See https://www.cyclescape.org/ for an example of such a peer-to-peer transport planning tool.
} 


\subsection{Demand for localised results}

With the emphasis shifting to reducing travel by building 'liveable' communities and enabling mode shift (Sallis et al. 2016), localised and geographically specific considerations may become increasingly prominent in future plans. To illustrate this point, imagine being the mayor of a major city that has declared a 'climate emergency' and who has been given the task of leading the transition away from fossil fuels (Hadfield and Cook 2019). Policies such as carbon taxes would undoubtedly be needed at the national level but your focus would naturally be on the bounds of the local authority over which you have some power. Except for specific national transport policies such as fuel tax, transport policies tend to have geographic outcomes (to build new cycle infrastructure, for example, which must go somewhere) and this is especially so for low-carbon transport plans which tend to operate over distances of hundreds of metres rather than dozens of kilometres, due to inherent limits in the speeds of active modes (Iacono et al. 2010).

Even high level national plans for a walking and cycling revolution must be implemented locally, down to the level of streets, as illustrated by the still ongoing local implementation of Dutch cycling ambitions (Pucher and Buehler 2008). The political-democratic and local-geographic aspects of transport planning can be considered in isolation, but an integrated approach is necessary for effective policies (Hull 2008). This is well illustrated by prominent Mayoral transport policies in cities such as London, ${ }^{3}$ Paris ${ }^{4}$, and Bogotá, ${ }^{5}$ where geographically specific interventions (such as congestion charges in carefully demarcated central zones) combined with citywide vision have enabled modal shift.

With issues such as climate change, air pollution, obesity and social inequalities high on the political agenda, and the benefits for 'early adopters' of evidence-based interventions to accelerate the shift away from the motor car in cities such as London, Paris and Bogotá, pressure is growing on local, city and national transport planning departments to act. But what should they do, and where should they intervene? Geographical data and to some extent analysis (e.g. calculating distances) was integral to this 'computational transport planning' activity, but input datasets were limited in size and accuracy. Partly in response to such drivers for geographic analysis in transport planning, there have been various attempts to define a more applied GIS approach transport research. Miller (1999) advocated a new field, GIS for Transport (GIS-T), posited as an academic field at the interface between transport planning and GIS. Although the label gained limited traction in academia or practice, Harvey Miller's call for a shift to methods and tools has been answered in the 2000s and 2010s by researchers who have developed ideas and software that transport

\footnotetext{
${ }^{3}$ Transport is a major electoral issue in London and the current Mayor, Sadiq Kahn, has made tackling air pollution a policy priority. See https://tfl.gov.uk/corporate/about-tfl/the-mayors-transport-strategy.

${ }^{4}$ The current Mayor of Paris, Anne Hidalgo, sees transport as a priority and has plans to make public transport free. See paris.fr.

${ }^{5}$ Bogotá has an innovative and prominent transport policy, led by the two times mayor Enrique Peñalosa, who has led the roll-out of major bus and cycleway projects in the city. See http://www.sitp.gov.co.
} 
planners can actually use, including the Australian Research Infrastructure Network (AURIN), which is widely used for transport planning and public health research in Australia (Pettit et al. 2014) and the Propensity to Cycle Tool (PCT, publicly available, including source code, at http://www.pct.bike) (Goodman et al. 2019).

\subsection{Technological drivers}

Technological change has increased the capabilities of transport planners since the the beginning of the discipline, with transport planning tasks being an early use case of mainframe computers (Boyce and Williams 2015). With unprecedented access to increasingly detailed datasets on transport behaviours and infrastructure, transport planners today require tools that enable them to make sense of this 'data revolution' (Transport Systems Catapult 2015). The sheer volume and complexity of new datasets require new approaches that can scale and integrate multiple data sources (Lovelace et al. 2016). Advances in software and hardware allow not only for current transport systems to be modelled at high temporal and geographic resolution, but for future scenarios and 'model experiments' to be developed, which can support identification and implementation of the most effective interventions (Klosterman 1999).

With the explosion in open source software, which has risen to prominence data science, policy, data and technological drivers are pushing for geographic analysis to be better integrated in transport planning tools, alongside wider shifts for towards more data driven, transparent and democratically accountable transport planning workflows. At present this dream is far from reality, despite the long history of geographic methods, public involvement and technological innovation in transport planning.

\section{The current landscape}

In broad terms, digital transport planning tools are like any other computer program in that they take inputs which are processed to generate outputs (Knuth 1997). The broader term 'transport model' is sometimes used interchangeably with transport software but in this paper we follow (Hollander 2016) in using 'model' to refer to the theories and mathematics underlying transport planning software, rather than the software that implements the model. ${ }^{6}$ In relation to the narrower concept of 'algorithm,' transport planning software can be seen as a computing environment or system that provides a user interface to run a range of algorithms interactively on a

\footnotetext{
6 There is of course a close relationship between transport planning software and models because theoretical models can inform the direction of software developments, as was the case with the development of spatial interaction models (Boyce and Williams 2015). Conversely, 'upstream' developments in computer languages affect the range of models that can be implemented, as can be seen with the current shift towards cloud-based and more visual and interactive transport models such as the open source Streetmix and the Institute of Transport Engineers endorsed StreetPlan tools for visualising 1D street layouts and cloud-based transport planning services such as Remix.
} 
range of input datasets to generate outputs that can feed into the wider transport planning process (Boyce and Williams 2015).

Software for transport planning can be grouped by the scale at which it operates, with broad categories being microscopic and macroscopic (macro) models (Kotusevski and Hawick 2009; Hildebrand and Hörtin 2014). Microscopic transport models represent individual vehicles on the road network and are therefore able to represent localised phenomena such as traffic congestion. Macro models, by contrast, represent aggregates of vehicular traffic over large spatial scales, in which "the total flow is studied" and behaviour of individual vehicles is omitted (Hildebrand and Hörtin 2014). Of course the distinction is, in reality, an oversimplification: there is a continuum between macro and microscopic transport models; advances in computing increasingly enable both approaches to be combined, enabling researchers to choose the most appropriate spatial scales for their application (Moeckel et al. 2018). The focus of this paper is on macro models which enable modelling of the implications of future changes in transport behaviour and infrastructure on flow at city scales, with results down the route network level (microscopic models tend to be used to model individual route segments and intersections), and their geographic analysis capabilities.

This history is detailed in Chapter 10 of Forecasting Urban Travel (Boyce and Williams 2015) called "Computing environment and travel forecasting software", which provides an insight into how software has been used in transport planning over the years. Of course, software development has always depended on the physical hardware on which it runs and the early days of transport planning software were characterised by bespoke programs running on mainframe computers and maintained by domain experts. Transport planning bodies and researchers in the USA led developments in the 1960s and 1970s when computers first started to be used for transport planning, when the main problem that they addressed was how to deal with the explosive growth in car ownership and use that was taking place during those decades. More overtly political factors also influenced the direction of transport planning software: "certain private firms complained to US DoT [Department of Transport] that its agencies were developing software in competition with the private sector," leading to the abandonment of publicly funded transport planning software development projects, notably UTPS (Boyce and Williams 2015). ${ }^{7}$ This transfer of transport planning software development to the private sector contrasts with the history of GIS. The example of GRASS (Geographic Resources Analysis Support System) illustrates this point and helps explain the dominance of proprietary software in transport planning. Like UTPS, GRASS was a publicly funded software project. Unlike UTPS, it was made freely available to the public and was open sourced (in 1999), meaning that it has been under continuous development by state, academic and commercial organisation since 1982 (Neteler and Mitasova 2008). Would the landscape of transport planning software have been different if the DoT had continued to fund software development projects? That question is outside

\footnotetext{
7 UTPS stands for the UMT (Urban Mass Transportation Administration, an agency of the DoT responsible for transport planning) Transportation Planning System (UTPS).
} 
Table 1 Sample of transport modelling software in use by practitioners, with citation counts based on citation from searches for the product name (plus company name for the common word 'cube') and 'transport planning'

\begin{tabular}{lllll}
\hline Software & Company/developer & Company HQ & Licence & Citations \\
\hline MATSim & TU Berlin & Germany & Open source (GPL) & 901 \\
Visum & PTV & Germany & Proprietary & 512 \\
ArcMap & ESRI & USA & Proprietary & 449 \\
SUMO & DLR & Germany & Open source (EPL) & 330 \\
TransCAD & Caliper & USA & Proprietary & 229 \\
Emme & INRO & Canada & Proprietary & 201 \\
Cube & Citilabs & USA & Proprietary & 91 \\
sDNA & Cardiff University & UK & Open source (GPL) & 27 \\
\hline
\end{tabular}

Data source: Google Scholar searches, August 2020

the scope of this paper. What is certain, however, is that software used in transport planning over the past three decades has been dominated by companies and that the sector has been slow to adopt open an open source approach.

In response to the 'siloed' development of GIS and transport software, there have been calls for greater integration. Loidl et al. (2016), building on the observation that "geography and GIS remained a niche topic within traditional transport modeling", made a case for strengthening the 'spatial perspective' in transport modelling. The paper emphasised the growing importance of well-defined data types, disaggregating detailed (and difficult to interpret) transport model outputs, and geographic data visualisation and concluded that much further research is needed: "future research and development is needed to combine geospatial functionalities with transport modeling, while providing an efficient, interactive, visual interface for data exploration, manipulation, analysis and visualization" (Loidl et al. 2016). Although the paper focussed on conceptual issues rather than software per-se, it did identify mention four open source programming languages that could provide the foundation for future developments, two of which ( $R$ and Python) are covered in the next section.

Data preprocessing and analysis stages are generally done in dedicated transport planning and spreadsheet software. Geographic analysis and cartographic visualisation stages are often done in a dedicated GIS. Some prominent transport planning software products, and levels of support for geographic data analysis, are summarised in Table 1, which shows that popular transport planning tools have differing levels of geographic capabilities.

An interesting observation is that the open source options-MATSim, SUMO and sDNA - all have limited 'in house' geographic capabilities. This can be explained by the 'Unix philosophy,' the second tenet of which is modularity, meaning that "each program should do one thing well", reducing duplication of effort and allowing the best tool to be used for each job (Gancarz 2003). The next section describes the this modularity in more detail, including outstanding support for geographic data in open source software. 
There are many barriers reducing access to prominent tools in the current landscape of transport planning. Proprietary tools are expensive (costing up to hundreds of dollars for a single license), ensuring that only a small fraction of transport planners, let alone the public, has access to them. Many proprietary tools are tied to a particular Windows, preventing use in on other operating systems such as Linux, Mac and FreeBSD. This reduces reproducibility of results and prevents 'citizen science' and educational projects that use the same tools as professional planners.

A wider barrier is that organisations' GIS and Transport functions tend to be siloed into their respective departments/teams with little communication between them, meaning that transport planners may not have access to the latest geographic data or software. ${ }^{8}$ This relates to tools because if transport planners and GIS analysts are using different programs for their work, transport planners will be less likely to collaborate with people with geographic analysis skills or identify potential geographic solutions to their domain-specific problems. The extent to which these barriers can be overcome by open source software ecosystems is explored in the next section.

\section{Open source tools for geographic analysis in transport planning}

Technological, environment and societal changes are driving demand for accessible tools for geographic analysis transport planning. This section reviews prominent open source tools that are already being used to tackle transport planning challenges. Open source tools for geographic analysis in transport planning have not emerged in a vacuum. They were developed in the wider landscape of open source software (Dhir and Dhir 2017).

These tools could be classified by the five main stages illustrated in Fig. 1 (data collection, processing, routing, modelling and visualisation). Instead, because many tools can be used in multiple stages, can be more usefully classified from the user's perspective. Based on open tools identified through web searches, they can be classified into the follow broad, and to some extent overlapping, ${ }^{9}$ user interface (UI) types (see Table 2):

- command-line interface (CLI) tools, primarily controlled by typing commands

- graphical user interface (GUI) tools, primarily controlled by mouse clicks

- web user interface (WUI) tools that users access through a web browser

- web application programming interfaces (API) that computers access over the web

In this paper we will focus on projects in the first three categories. Numerous open source 'routing engine' projects provide a range of high performance routing and other transport data analysis services via a web application programming interface

\footnotetext{
8 Thanks to Crispin Cooper, author of sDNA, for raising this barrier.

9 Some tools can be used through multiple interfaces but most have a dominant interface type.
} 
(API). While technically these can be used for geographic analysis tasks, they are more commonly used by transport planners as remote services, and are usually the preserve of software developers, so were excluded from Table 2.

\subsection{Defining open source}

Before describing open source tools for transport planning, classified by their main user interface, is worth considering what 'open source' means.

Open source software differs from proprietary software in that users are free to see, download and modify the source code. Freedom is central to open source software, which is sometimes referred to simply as 'free software', defined by the Free Software Foundation (FSF) as follows: ${ }^{10}$

software that gives you the user the freedom to share, study and modify it.

This adaptability is conducive to collaboration, the creation of mutually supportive user/developer communities and rapid evolution, making open source software ecosystems fast moving and highly diverse. It is impossible to discuss all software options that could be used for geographic transport planning: there are literally thousands of software projects written in dozens of programming languages, many of which are no longer actively maintained (Coelho et al. 2020). Transport planners should use solutions that are future proof and actively maintained.

\subsection{Methods to identify open source tools}

To identify open source tools for transport planning, a search approach was used to incorporate projects that have been written-up in the academic literature, and projects which exist only as software projects, with a minimum level of popularity. The method was as follows:

1. Undertake searches of Google Scholar, DuckDuckGo and the popular code hosting platform with search terms set to identify open source projects for transport planning.

2. Combine results from the searches into a single dataset and rank the projects according to evidence of usage.

3. Verify that the projects are open source and actively maintained by analysis of package documentation and source code.

4. Classify and the projects based on their main user interface, resulting in Table 2 (see open_tools.csv for a more complete list that includes web APIs). These tools are described in more detail in the following three sections.

The following search terms were used to find relevant projects using Google Scholar, the result of a search shown in Fig. 2:

${ }_{10}$ See https://www.fsf.org/about/what-is-free-software for a full definition and context. 


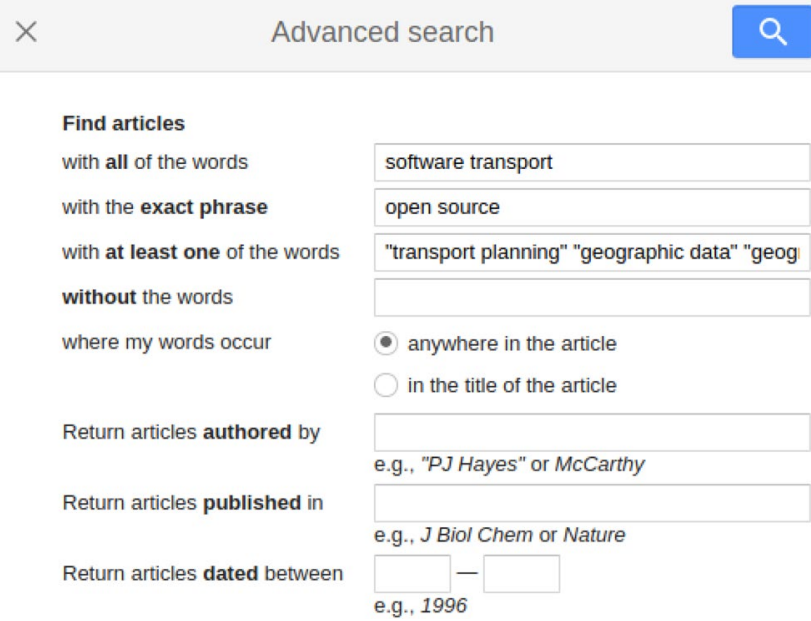

Fig. 2 Illustration of the Google Scholar search terms used to identify open source software for geographic analysis in transport planning

software transport "open source" "transport planning" OR "geographic data" OR "geographic analysis" OR "spatial data" OR "spatial network"

To identify open source projects on GitHub's advanced search page a 'snowball' method, analogous to that used by Grabowicz et al. (2012) in the context of social media, was used. The 'topic' descriptions of previously identified open tools were used to identify additional projects and search terms. This method worked as follows:

- The GitHub page of the previously identified project stplanr project was visited.

- One of the 'topics' in the stplanr repository was was the broader term transport, which was used to identify the SUMO project

- The SUMO project had the topic 'simulation', leading to the discovery of the A/B Street project

The list of GitHub topics used to identify projects was as follows (manual reading of the README for each project was used to confirm if the projects were related to transport planning, many were not, e.g. because they were for web transport rather than transport planning):

transport planning, transport, transportation-planning, traffic-simulation, simulation, trajectory

To overcome the limitation that not all open source software projects are hosted on GitHub or described in academic papers, snowballing via web pages such as 
Table 2 Open source tools for geographic analysis in transport planning, based on data from Google Scholar, GitHub and web searches and classified in by their primary user interface

\begin{tabular}{|c|c|c|c|c|c|c|}
\hline Tool & Type & Licence & Language & Stars & Citations & References \\
\hline \multicolumn{7}{|l|}{$C L I$} \\
\hline OSMnx & Python package & MIT & Python & 2496 & 302 & Boeing (2017) \\
\hline SUMO & Standalone & EPL-2.0 & $\mathrm{C}++$ & 736 & 219 & Lopez et al. (2018) \\
\hline UrbanSim & Python package & AGPLv3 & Python & 310 & 1444 & Waddell (2002) \\
\hline MovingPandas & Python package & BSD-3 & Python & 307 & 6 & Graser (2019) \\
\hline MATSim & Standalone & GPLv2 & Java & 285 & 564 & Horni et al. (2016) \\
\hline Scikit-mobility & Python package & BSD-3 & Python & 251 & 1 & $\begin{array}{l}\text { Pappalardo et al. } \\
\text { (2019) }\end{array}$ \\
\hline stplanr & $\mathrm{R}$ package & MIT & $\mathrm{R}$ & 201 & 9 & $\begin{array}{l}\text { Lovelace and Elli- } \\
\text { son (2018) }\end{array}$ \\
\hline momepy & Python package & MIT & Python & 133 & 3 & Fleischmann (2019) \\
\hline \multirow[t]{2}{*}{ Trip-simulator } & $\begin{array}{l}\text { JavaScript pack- } \\
\text { age }\end{array}$ & MIT & JavaScript & 117 & NA & NA \\
\hline & Python package & AGPLv3 & Python & 105 & 12 & $\begin{array}{l}\text { Blanchard and } \\
\text { Waddell (2017) }\end{array}$ \\
\hline spaghetti & Python package & BSD-3 & Python & 60 & 0 & $\begin{array}{l}\text { Gaboardi et al. } \\
\text { (2018) }\end{array}$ \\
\hline urbanpy & Python package & MIT & Python & 16 & NA & NA \\
\hline \multicolumn{7}{|l|}{$G U I$} \\
\hline ABStreet & Standalone & Apache-2.0 & Rust & 4896 & NA & NA \\
\hline Veins & Standalone & GPLv2 & $\mathrm{C}++$ & 155 & NA & NA \\
\hline AequilibraE & QGIS plugin & Custom & Python & 57 & 3 & Camargo (2015) \\
\hline QNEAT3 & QGIS plugin & GPLv3 & Python & 35 & NA & NA \\
\hline Networks plugin & QGIS plugin & GPLv3 & Python & 9 & NA & NA \\
\hline sDNA & QGIS plugin & GPLv3 & $\mathrm{C}++$ & 9 & 27 & $\begin{array}{l}\text { Cooper and Chiara- } \\
\text { dia }(2020)\end{array}$ \\
\hline AwaP & QGIS plugin & GPLv3 & Python & 3 & 2 & $\begin{array}{l}\text { Majic and Pafka } \\
\text { (2019) }\end{array}$ \\
\hline \multicolumn{7}{|l|}{$W U I$} \\
\hline Citybound & Standalone & AGPLv3 & Rust & 6124 & NA & NA \\
\hline StreetMix & Hosted service & BSD-3 & JavaScript & 440 & 6 & Riggs et al. (2016) \\
\hline flowmap.blue & Standalone & MIT & TypeScript & 90 & NA & NA \\
\hline $\begin{array}{l}\text { Conveyal Analy- } \\
\text { sis }\end{array}$ & Hosted service & MIT & Java & 19 & NA & NA \\
\hline PCT & Hosted service & AGPLv3 & $\mathrm{R}$ & 16 & 66 & $\begin{array}{l}\text { Lovelace et al. } \\
\text { (2017) }\end{array}$ \\
\hline TrajAnalytics & Standalone & BSD-3 & JavaScript & NA & 0 & $\begin{array}{l}\text { Shamal et al. } \\
\text { (2019) }\end{array}$ \\
\hline
\end{tabular}

CLI, GUI and WUI refer to command-line, graphical user and web user interfaces respectively 
the QGIS plugin homepage, links in project README files and social media were used to find additional projects. Only projects with the following criteria were included (see open_tools.csv for online version):

1. The tool was designed to support transport planning using geographic data analysis and supports the design and placement of physical infrastructure for urban mobility, based on the project's website or code repository

2. Evidence that the tool is being used in practice, via citations, 'stars' or other type of 'upvote'

3. Evidence that the tool is actively maintained, with activity in the last 12 months

4. Availability of source code with a visible open source license

A secondary filter was used to focus attention on tools for analysis: projects whose primary purpose is to provide an interface to an existing software/services, such as the R package opentripplanner (e.g. Morgan et al. 2019; Giraud 2019) and routing engines (Luxen and Vetter 2011; Padgham 2019) are omitted from Table 2 for brevity (routing engines are mentioned in the final section of the paper). Tools can be classified in a variety of ways from a developer's perspective including sometimes tribal 'ecosystems' such as R packages, Python packages and QGIS plugins. From a transport planner's perspective, however, the technology or developer community from which tools emerge may be irrelevant: what is important is what the tool can do and its ease-of-use. We therefore describe the tools in order of their primary user interface, in chronological order of the interface's development (CLIs predate GUIs which predate WUIs), acknowledging the fact that most tools with a prominent GUI and WUI can also be used from the command line. While sDNA and AequilibraE can be used from the command-line, their documentation suggests they are more likely to be used from graphical interfaces via QGIS plugins, resulting in the categorisation shown in Table 2.

It should be clear that the 'Type' and 'Language' values shown in Table 2 are also fuzzy: open source software is by nature modular and flexible, meaning that the same piece of code can take multiple different forms and the same method can be implemented in multiple languages. The AequilibraE QGIS plugin (Camargo 2015), for example, is also a Python package. Conversely, the MovingPandas Python package by Graser (2019) is also a QGIS plugin. The point is that the most prominent category into which each project seemed to fall, based on documentation, was used. The rest of this section outlines some of the capabilities of each tool presented in Table 2 based on the author's reading of easily available documentation: due to time constraints no systematic installation tests or benchmarks were undertaken, although this could be a direction of future research.

An interesting insight provided by the popularity metrics of 'Stars' (meaning the number of people who had 'starred' the project on GitHub) and Citations (to the main paper outlining the tool, where available) as of September 2020 is that the choice of metric has a large impact on perceived popularity. While MatSIM is perhaps the tool in Table 2 that has most uptake in applied transport planning, it had 
only a moderate number of Stars (285) compared with the number of papers citing the tool's main reference the tool, which is in itself a free and open resource (Horni et al. 2016). A/B Street, by contrast, had more than twenty times the number of Stars on GitHub but no academic paper that could be found in the public domain at the time of writing. This highlights the fact that different user communities visit different forums and, furthermore, many transport practitioners will neither write academic papers not be active GitHub users, making the uptake of different software projects even harder to monitor, an issue we return to in Sect. 5.

\subsection{Command-line interface (CLI) tools}

Tools based on a command line interface (CLI) are designed to be controlled primarily by typing commands. CLIs predate graphical user interfaces (GUIs), which are controlled by 'pointing and clicking' (Sherman 2008). CLIs can take time to learn, especially for people who have been trained on GUI-based software such as Microsoft Word. After overcoming often steep 'learning curves,' the advantages of CLI-based tools for users become substantial. The approach can be highly productive, with hundreds of commands only a few keystrokes away and the benefits of reproducibility and scalability associated with representing computational workflows in code. Programming also provides flexibility: the user is not constrained by the options provided in the GUI and in many CLI-based tools can define new functions. The approach also has advantages for developers: it is substantially easier to write software without the burden of having to develop a GUI, reducing the barrier to entry for potential contributors. Ease of development explains why CLIs represent the most common type of open source tool for geographic analysis.

The longest standing and still actively maintained CLI tools for geographic analysis in transport planning shown in Table 2 are SUMO (first released in 2001) and MATSim (first released in 2006). Both projects operate at the 'microscropic' (street) level and simulate individual vehicles at high spatial and temporal resolution, although the emphasis of MATSim is more on citywide analysis compared with the emphasis on modelling traffic at junctions in SUMO. There is evidence of uptake of both projects in applied transport planning contexts, with MATSim in particular being cited in dozens of applied transport planning papers. Neither project focusses on geographic analysis but both rely on geographic inputs (detailed road geometries) and produce geographic outputs.

MATSim, which stands for Multi-Agent Transport Simulation, is perhaps the more ambitious project, enabling the transport systems of entire cities to be simulated, creating opportunities for detailed model experiments based on transport networks that can be edited using a plugin to the JOSM GIS (Horni et al. 2016). SUMO is focussed on modelling traffic on road segments and junctions and although the emphasis is not on geographic analysis, the inclusion of a geographic road network editor (called NETEDIT) means that the tool can be used to analyse geographic scenarios of change (Lopez et al. 2018). With complex installation and usage instructions, SUMO and MATSim are both aimed at advanced users. This has the advantage of enabling many research and (particularly in the case of MATSim) applied 
use cases due to the flexibility of the tools, but has the disadvantage of reducing accessibility.

The remaining CLI-based tools in Table 2 are smaller, simpler and more accessible R/Python packages that fit within the framework of these pre-existing open source software ecosystems. OSMnx is a Python package for downloading and analysing transport networks from OpenStreetMap that has a focus on urban transport network analysis (Boeing 2017). OSMnx has been used for a wide range of research and real-world applications, with a focus on spatial network analysis via functions for calculating a range of transport network measures. Movingpandas is a Python package and QGIS plug-in for visualising a wide range of movement datasets, with a focus on trajectory data (Graser 2019). momepy is a Python package for measuring 'urban morphology,' meaning the measurement and analysis of collections of geographic entities that constitute cities (Fleischmann 2019).

The other Python packages in Table 2 have broader (and to some extent overlapping) remits, aiming to support a range of transport planning objectives. UrbanSim and UrbanAccess are Python packages that are part of the project, with the former oriented towards statistical analysis of citywide transport systems and the latter focused on analyzing geographic transport network data from an accessibility perspective. The documentation describing these tool highlights their ability to assist metropolitan planning organizations (MPOs) to prioritise investments that costeffectively increase accessibility for those most in need (Blanchard and Waddell 2017). In addition to using OSM data, UrbanAccess can import and process GTFS data to calculate multi-modal travel times and other metrics. UrbanPy has similar objectives and includes functionality for spinning-up Docker containers to do routing using the OSRM routing engine, highlighting the interoperability between open source tools.

Like momepy, the spaghetti package (which stands for SPAtial GrapHs: nETworks, Topology, \& Inference) is focussed on street network analysis, but focusses less on urban morphology and more on segment-level statistics (Gaboardi et al. 2018). scikit-mobility implements a framework for statistical modelling of travel behaviour, including functions for estimating movement between geographic zones using spatial interaction models, as well as route assignment (Pappalardo et al. 2019).

The JavaScript package Trip-simulator, from the not-for-profit organisation Shared Streets, enables geographic analysis for transport planning by simulating GPS flows on street networks. Its command-line interface allows a wide variety of trip types and volumes to be simulated which can, given a new street network layout, be used to estimate the impact of changes to the network.

The remaining two CLI-based tools in Table 2 are $\mathrm{R}$ packages focussed on applied transport planning. stplanr (which stands for sustainable transport planning with $\mathrm{R}$ ) contains a range of functions for processing origin-destination, routes and route networks. The package takes an explicitly geographic approach to transport planning and many of the functions use geographic operations such as buffers and spatial aggregation in workflows that start with origin-destination data and end with estimates of travel demand down to the route network level under different scenarios of change (Lovelace and Ellison 2018). Opentripplanner is an R package 
for multi-modal routing and accessibility analysis that provides an interface to the OpenTripPlanner Java library, enabling not only calculation of travel times and route geometries but also monetary costs and accessibility isochrone maps where GTFS data allow (Morgan et al. 2019).

\subsection{Graphical user interface (GUI) tools}

Other than A/B Street, all of the GUI-based tools presented in Table 2 are QGIS plugin. This came as a surprise: given the dominance of GUIs in many areas of computing one would expect a range of stand-alone transport planning tools to have been developed (the criterion that tools must be actively maintained to be considered explains the exclusion of some tools such as Tranus (de la Barra et al. 1984)).

A/B Street does not market itself as a transport planning tool but instead as a game and educational tool. However, that does not mean that it lacks capabilities. A/B Street combines the real-time capabilities of MATSim with the usability of online tools such as Streetmix, discussed in the next section, taking a 'SimCity' approach to transport planning, while still allowing the user to zoom in to single vehicles (while they are in motion via a moving camera!) and change the geometries of street layouts with an intuitive in-built editor.

QGIS plugins for transport planning are explicitly focussed on geographic analysis for transport planning. AequilibraE, QNEAT3 and the Networks plugins provide various transport planning tools from the mature and popular QGIS GUI-based Geographic Information System (GIS). AequilibraE provides a broad range of functions for processing transport networks and assigning traffic (Camargo 2015), as detailed in the project's substantial documentation website. QNEAT3 provides a narrower but well documented set of algorithms for transport planning applications, including shortest path, network buffers and OD matrix visualisation. The Networks plugin uses an interface to external software Mulsiw to enable multi-modal routing and GTFS data import. The AwaP plugin uses data on urban 'blocks' (typically buildings) to calculate indicators relating to walkability. The tool can been used to compare the urban morphologies of different areas cities from a walkability perspective (Majic and Pafka 2019).

Finally, the sDNA QGIS plugin provides an interface to the $\mathrm{C}++$ project sDNA, a tool for spatial network analysis that has been developed to support transport planning for walking and cycling (Cooper and Chiaradia 2020). A range of route network analysis functions are available, enabling the user to parameterise models to best represent travel behaviour at city scales base on the high performance routing between every vertex on the network. By changing network characteristics and geometries or adjusting parameters, model experiments can be undertaken in sDNA to represent scenarios of change (Cooper 2018).

\subsection{Web user interface (WUI) tools}

Installing and running code on sufficiently powerful computers has long been a barrier preventing people from accessing software, and transport planning tools are no 
exception. In this context web user interfaces (WUIs, by which I mean an in-browser graphical user interface rather than a web API) can provide multiple advantages in terms of participatory planning (although cloud-based solutions also pose risks in terms of concentration of processing and economic power).

Like A/B Street, CityBound takes a gaming approach to transport planning, with an interactive editor and an agent-based approach that allows hundreds of vehicles to interact on city scale networks in real-time. Perhaps its most interesting feature from a transport planner's perspective is the editing framework, which offers "the power and expressiveness of professional CAD tools while being much more intuitive and fun to use". Also like $A / B$ Street the project does not originate from a transport planning context, instead approaching city planning from a computer science perspective using recent developments in digital technology such as WebAssembly to push boundaries, which in part explains the project's popularity among developers as evidenced by the fact it has more than 6k 'Stars' on GitHub.

Streetmix is primarily available and used as a free and open web service hosted at streetmix.net, but it is also an open source software project supported by free software giant Mozilla that enables anyone to create a locally hosted instance of the service. Unlike the other projects listed in Table 2, Streetmix does not use 2 dimensional (longitude/latitude) data but instead allows the user to interactively edit a 1D street profile, from the edge of buildings on one side to the other side. You can add pavements, cycleways, aesthetic features such as trees and other items to support more sustainable planning policies and designs (Riggs et al. 2016). As discussed in Sect. 5, the combination of the emphasis on participatory design for sustainable futures in Streetmix with the technology for 2D (and even 3D) intiutive editing in CityBound represents a promising possibility for future research and development.

Conveyal Analysis represents a step in that direction, providing a hosted service for city-wide scenarios of change. With only 19 Stars on GitHub and limited documentation, however, the Analysis tool has some way to go before it builds a 'community of practice' of the type enjoyed by more established and well-documented projects such as MATSim.

The JavaScript/TypeScript-based projects flowmap.blue and TrajAnalytics are interactive, web-based geographic mobility data visualisation tools at opposite ends of the spectrum in terms of size and complexity. flowmap.blue is a lightweight tool that focusses on ease of use and, via an R package of the same name, inter-operability for people working with origin-destination data. TrajAnalytics is a large (83 MB zipped) project providing a visualisation framework for displaying and analysing large trajectory datasets. Unlike Streetmix, which focusses on the individual street level, both projects are designed for visualising citywide and regional scale transport systems.

The Propensity to Cycle Tool (PCT) is an interactive map-based web tool designed to support cost effective investment in cycling infrastructure (Lovelace et al. 2017). The emphasis is on where to build to maximise cycling uptake. By exploring scenarios of change including Go Dutch - in which cycling levels are simulated to grow to Dutch levels nationwide-planners, active travel advocates and other stakeholders build business cases for investment along desire lines with high 


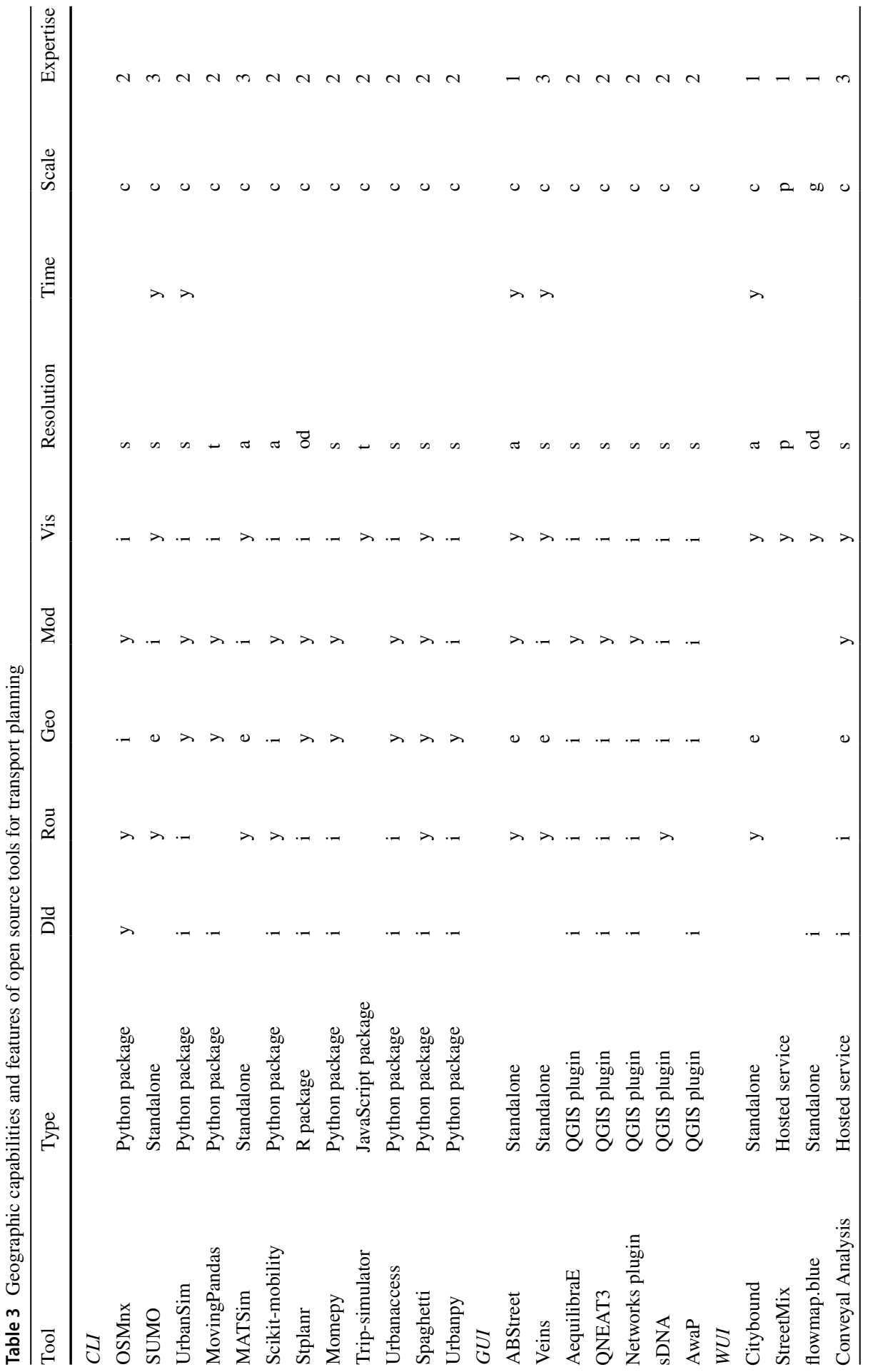




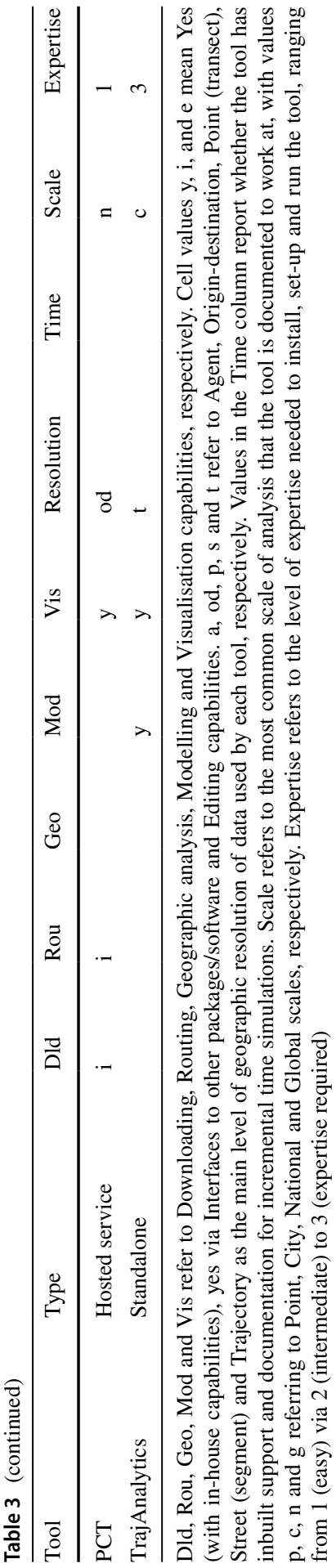


cycling potential and better understand health and environmental benefits of interventions in different places.

\subsection{Geographic capabilities}

The brief descriptions of CLI, GUI and WUI-based tools for transport planning above show diversity of approaches to geographic data, ranging from 1D editing in Streetmix to full geographic data editing and analysis functionality available to users of QGIS-based tools. With reference to the transport planning process shown in Fig. 1, the geographic capabilities of the tools are shown in Table 3. The columns in 3 broadly match the main stages of transport planning as follows:

(1) data collection: supported by download (Dld) functionality

(2) modelling/analysis: supported by routing (Rou) and geographic analysis (Geo)

(3) evaluation: supported by modelling and data analysis (Mod) capabilities

(4) implementation of solutions: supported by visualisation (Vis)

Additional important considerations include the geographic resolution, support for time series analysis (over seconds to years), the scale at which the tools are documented to run at and the level of expertise needed to install, set-up and use the tool. Many tools provide functionality through documented interfaces to other packages. $\mathrm{R}$ has a mature ecosystem of packages for geographic analysis, with particular strengths in statistical analysis Bivand (2020) and visualisation (Lovelace et al. 2019, Chapter 8). Likewise, there is a growing ecosystem of Python packages for geographic analysis (Garrard 2016), some of which are available as QGIS plugins, placing the user in an advance GIS.

Another key finding from Table 3 is that there is no single tool that every desirable feature of tools for geographic analysis in transport planning. There is generally a trade-off between the complexity of the tool and ease-of-use, with MATSim and SUMO being sophisticated yet hard to use and Streetmix providing an intuitive interface yet limited geographic capabilities, for example. There are exceptions: $A / B$ Street provides a user friendly interface and even a 'demo' mode inspired by computer game design yet also has sophisticated functionality, although due to the nascent nature of the project and focus on education/fun rather than real-world transport planning these capabilities have yet to be documented in applied settings.

Table 3 shows that there is great diversity of open source tools, even within the limited and still nascent niche of tools for geographic analysis in transport planning. There seems to be more diversity within each software ecosystems such as $\mathrm{R}$ packages, Python packages and QGIS plugins than between them, despite the fact that software developers within each ecosystem are linked by an overarching language/approach. Software is not developed in isolation but in a social context and the collaborative nature of open source tools tends to encourage solutions that are mutually supportive rather than competing (Dhir and Dhir 2017). Indeed, many of the tools presented in Table 3 have a particular speciality, ranging from 
analysis of citywide transport networks in OSMnx (Boeing 2017) to the analysis of cycling potential in the PCT (Lovelace et al. 2017) and the visualisation of origin-destination data in flowmap.blue.

A few of the tools can be seen as general purpose transport planning tools, with particular strengths. Veins (which uses SUMO behind the scenes), MATSim and A/B Street are well suited to a wide range of geographic transport planning tasks, ranging from the simulation of the impact of new infrastructure on the flow of individual vehicles to city-wide impacts of new policies. All three have mechanisms to not only describe but to change transport networks interactively and all can work on scales ranging from single junctions to entire cities (although at the time of writing, A/B Street struggles to represent the central areas of large cities such as London, the performance of the other tools on large cities is not known). Tools focussed on origin-destination data such as the PCT and flowmap.blue are not constrained by the need to visualise complex city networks, and can show the transport cities of entire countries.

This raises the question of scale. Clearly, different tools have different capabilities and most tools can be used to analyse phenomena at more than one scale of analysis. Furthermore, although a tool has a 'most common scale' that does not mean it cannot be used at larger or smaller scales. MATSim, for example, is most often used to study city-level phenomena and requires substantial computing resources to study regional or even national systems at high temporal resolution, but that does not mean it cannot be done if sufficiently powerful hardware and set-up resources are available (the same point applies to the other microsimulation tools SUMO, A/B Street and Veins). And although tools have a main level (Resolution) of analysis, that does not stop them from using or producing datasets at higher resolution, the PCT's production of data at the route network segment (s) level using OD data as inputs being a case in point (Morgan and Lovelace 2020).

\section{Discussion and conclusion}

Geographic analysis is an important yet often under-appreciated aspect of transport planning, and looks set to play a more prominent role in the future. In the context of urgent policy drivers-including the obesity crisis, air pollution concerns and the climate emergency that has been declared by some city authorities-many transport planners have been tasked with new sustainable transport targets, including reduced private car use and increasing levels of walking and cycling (Hickman et al. 2011). In the context of calls for evidence-based policy, open data and citizen science (Banister 2008; Peters 2020) - and political commitments to and actions implementing such principles by actors at state and regional levels (Monbiot 2017; Peters 2020) there is a growing onus on practitioners to provide solutions that are transparent, accessible and, participatory.

This poses a challenge to the vendors of proprietary transport planning software, which tends to be expensive and thereby inaccessible to most people, monolithic and (to a greater or lesser extent) limited in terms of geographic capabilities, particularly in relation to publicly accessible interactive visualisation and adaptability. The 
new planning priorities also present opportunities, in terms of institutional processes (Beddoe et al. 2009), but also new technologies that are explicitly designed to enable more participatory, transparent and community-driven transport planning processes. Game-like approaches to city/street analysis tools such as A/B Street, CityBound and the intuitive and popular Streetmix web service demonstrate the huge potential for tools to revolutionise not only how transport plans are developed but who can be involved in the planning process. This raises the question: what would a tool for geographic analysis in transport planning that was as powerful and 'playable' as $A / B$ Street yet as user friendly as Streetmix look like? Each of the projects outlined in this paper show that open source solutions to transport planning needs are advanced, and in a growing number of areas more advanced, than propriety software. This raises the question: what would a completely open source, participatory and reproducible landscape for transport planning look like?

Answers to these broader questions are beyond the scope of this paper, but the tools and ecosystems outlined in previous sections provide an indication of what is possible. Insights from open tools that are already widely used suggest that the continued uptake of open tools will have substantial benefits in the coming years and decades. Benefits of the free and open source approach range from the increased opportunities for participation that tools such as the PCT and Streetmix enable, to the possibilities for extending capabilities, as shown by the various plug-ins that have been developed for tools such as QGIS and MATSim.

The research presented in this paper suggests that a shift to open source planning tools in general, and open source tools for local planning in particular, could tackle wider problems, including the 'crisis of participatory planning' and feelings of dis-empowerment due to lack of opportunities to engage in democratic processes (Legacy 2016; Monbiot 2017). Open tools can also support data and software literacy (Christozov and Rasheva-Yordanova 2017). A key feature of geographic tools for transport planning is that they encourage users to focus on local areas, moving beyond 'one size fits all', enabling diverse designs to fit a wide range of diverse local needs. A key feature of open tools, and especially open online tools that are easy to use, is that anyone can use them, encouraging citizen engagement.

From a user perspective, Sect. 4 demonstrates that a wide range tools are available. A potential limitation of the paradigm shift to open source is the time taken to understand which tool or combination of tools is most appropriate particular transport planning tasks. This can take time. On the other hand, a benefit of the range of free and open options offered is that users are encouraged to think about and better understand the tools they are using rather than blindly using established (and perhaps expensive and dated) 'tools of the trade'. From a developer perspective, the community of support and feedback may be more important than current functionality of tools. The literature shows that R, Python and QGIS communities have already developed several tools for transport planning that, when combined with other open source solutions, can solve a wide range of spatial transport planning problems.

Many other tools and communities exist. A limitation of the paper is that it is not comprehensive, omitting due to space constraints consideration of routing engines such as pgRouting, OSRM, GraphHopper (and related project OpenRouteService), 
OpenTripPlanner, Valhalla and the recently developed motis ${ }^{11}$ and tools that can be applied to transport planning but which were not designed for transport planning such as the gama platform and general purpose geographic data processing projects. Future research could review and benchmark such alternative tools for transport planning to provide valuable insight into which tools work best for different applications including, critically, how to rapidly decarbonise transport systems worldwide (Hickman et al. 2011).

In terms of further research, a hypothesis raised in this paper is that open source tools for transport planning, underpinned by the FOSS philosophy described in Sect. 4, will continue to gain market share in academic, public sector and consultancy applications. The paper supports the characterisation of open source software as collaborative, innovative and evolving (Gancarz 2003). Will these features of open source tools allow them to out-compete and eventually dominate in the field of transport planning — as has already happened in fields including machine learning (e.g. Abadi et al. 2016) and web development (e.g. Grinberg 2018; Wickham 2020)? Only time and much-needed further research into the topic will tell. Regardless of the answer, this paper has conclusively found that high-performance and innovative open source solutions are already available in the 'ecological niche' of geographic analysis for transport planning. The nascent and rapidly evolving nature of open source transport planning ecosystems means that there are many fruitful directions of future research, asking a wide range of related questions, including:

- What are the relative merits of different tools and combinations of tools for different transport planning applications, in terms of criteria such as computer/programmer efficiency and public accessibility?

- What scope is there for greater integration and collaboration between tools, building on the modular and 'pluginable' nature of open source software (this questions raises the prospect R/Python/QGIS/other interfaces to established transport tools such as MATSim, SUMO and sDNA)?

- How can the growth of open source solutions for geographic transport data analysis be monitored, e.g. to identify 'tipping points' in uptake?

- What are the barriers to uptake and 'discoverability' of leading open source tools, including in relation to documentation and case studies?

- In which contexts-e.g. along wealthy/low income, urban/rural, democratic/dictatorship continua-are open source tools for transport planning, and evidencebased decision-making in general, most effective and most needed?

This is clearly a multi-disciplinary area of research, and it is not immediately clear which methodological approaches-ranging from action-based research developing "practical solutions to issues of pressing concern," e.g. by creating or contributing to the source code underpinning open source tools (Brydon-Miller et al. 2003), to more conventional literature/software reviews of emerging ecosystems (e.g. Joo et al. 2020).

\footnotetext{
11 See https://jakobmiksch.eu/post/openstreetmap_routing/ for an overview or routing engines for OpenStreetMap data.
} 
Technical/computing approaches could usefully tackle more objective questions, such as the relative performance of different routing engines and transport planning APIs. Indeed, there is a need research evaluating the potential of 'WebAPI' based tools for transport planning such as OpenTripPlanner, mentioned in the online version of Table 2 but not discussed in this paper due to space constraints.

Returning to the 'big picture' introduced in Sect. 1, it is clear that there are strong arguments for a paradigm shift in transport planning overall. Academic attention has tended to focus on changes that are needed in the overall planning process (Banister 2008; Legacy 2016) rather than changes that are needed in the transport planning 'tools of the trade,' notwithstanding research advocating for change in transport modelling from practitioner (e.g. Hollander 2016), academic (e.g. Lovelace et al. 2020) and advocacy (e.g. Beimborn and Kennedy 1996) perspectives.

Building on prior research and a review of existing open source options, this paper highlights the importance of not only processes and models, but also the tools used for designing geographically specific transport plans. Open source tools generate evidence that is more likely to be rigorous, transparent, reproducible and shared than evidence generated by the established proprietary tools (Peters 2020; Brunsdon and Comber 2020). Transport interventions based on such open evidence are more likely to be effective at meeting policy objectives. Effective interventions are necessary to improve the environmental and health performance of transport systems worldwide, to reduce lives lost due to climate change and non-communicable disease. This paper therefore concludes that open source tools for geographic analysis in transport planning can support emerging environmental, health and social objectives. In other words - alongside wider political and institutional shifts to decarbonise the economy (Beddoe et al. 2009; Litman 2007)_open source software can, in addition to providing cost-effective solutions to twenty-first century transport planning needs, save lives.

Open Access This article is licensed under a Creative Commons Attribution 4.0 International License, which permits use, sharing, adaptation, distribution and reproduction in any medium or format, as long as you give appropriate credit to the original author(s) and the source, provide a link to the Creative Commons licence, and indicate if changes were made. The images or other third party material in this article are included in the article's Creative Commons licence, unless indicated otherwise in a credit line to the material. If material is not included in the article's Creative Commons licence and your intended use is not permitted by statutory regulation or exceeds the permitted use, you will need to obtain permission directly from the copyright holder. To view a copy of this licence, visit http://creativecommons.org/licen ses/by/4.0/.

\section{References}

Abadi M, Agarwal A, Barham P, Brevdo E, Chen Z, Citro C, Corrado GS, et al (2016) TensorFlow: largescale machine learning on heterogeneous distributed systems. arXiv:1603.04467 [cs]

Anderson LD (1991) Applying geographic information systems to transportation planning. Transport Res Rec, No. 1305

Aryandoust A, van Vliet O, Patt A (2019) City-scale car traffic and parking density maps from uber movement travel time data. Sci Data 6(1):1-18. https://doi.org/10.1038/s41597-019-0159-6

Banister D (2008) The sustainable mobility paradigm. Transp Policy 15(2):73-80 
Barth'elemy M (2011) Spatial networks. Phys Rep 499(1):1-101

Batty M (1995) Planning support systems and the new logic of computation. Reg Dev Dial 16(1):1-17

Beddoe R, Costanza R, Farley J, Garza E, Kent J, Kubiszewski I, Martinez L et al (2009) Overcoming systemic roadblocks to sustainability: the evolutionary redesign of worldviews, institutions, and technologies. Proc Natl Acad Sci 106(8):2483-89. https://doi.org/10.1073/pnas.0812570106

Beimborn E, Kennedy R (1996) Inside the blackbox: making transportation models work for livable communities. Citizens Better Environ

Bivand RS (2020) Progress in the R ecosystem for representing and handling spatial data. J Geogr Syst. https://doi.org/10.1007/s10109-020-00336-0

Blanchard SD, Waddell P (2017) Urbanaccess: generalized methodology for measuring regional accessibility with an integrated pedestrian and transit network. Transp Res Rec 2653(1):35-44

Boeing G (2017) OSMnx: new methods for acquiring, constructing, analyzing, and visualizing complex street networks. Comput Environ Urban Syst 65:126-39. https://doi.org/10.1016/j.compenvurb sys.2017.05.004

Boyce DE, Williams HCWL (2015) Forecasting urban travel: past, present and future. Edward Elgar Publishing, Cheltenham

Brunsdon C, Comber A (2020) Opening practice: supporting reproducibility and critical spatial data science. J Geogr Syst. https://doi.org/10.1007/s10109-020-00334-2

Brydon-Miller M, Greenwood D, Maguire P (2003) Why action research? Act Res 1(1):9-28. https://doi. org/10.1177/14767503030011002

Camargo P (2015) AequilibraE: a free QGIS add-on for transportation modeling. Foss4g North America

Christozov D, Rasheva-Yordanova K (2017) Data literacy. Int J Dig Lit Dig Compet 8(2):14-38. https:// doi.org/10.4018/ijdldc.2017040102

Coelho J, Valente MT, Milen L, Silva LL (2020) Is this GitHub project maintained? Measuring the level of maintenance activity of open-source projects. Inf Softw Technol 122:106274. https://doi. org/10.1016/j.infsof.2020.106274

Cooper CHV (2018) Predictive spatial network analysis for high-resolution transport modeling, applied to cyclist flows, mode choice, and targeting investment. Int J Sustain Transp. https://doi. org/10.1080/15568318.2018.1432730

Cooper CHV, Chiaradia AJF (2020) sDNA: 3-d spatial network analysis for GIS, CAD, command line \& python. SoftwareX 12:100525. https://doi.org/10.1016/j.softx.2020.100525

de Dios Ort'uzar J, Willumsen LG (2011) Modelling transport, 4th edn. Wiley, Chichester

de la Barra T, P'erez B, Vera N (1984) TRANUS-J: putting large models into small computers. Environ Plan B Plan Des 11(1):87-101. https://doi.org/10.1068/b110087

Department for Transport (2020) Decarbonising transport: setting the challenge. Department for Transport

Dhir S, Dhir S (2017) Adoption of open-source software versus proprietary software: an exploratory study. Strat Change 26(4):363-71. https://doi.org/10.1002/jsc.2137

Ebdon D (1992) SPANSA quadtree-based GIS. Comput Geosci GIS Des Model 18(4):471-75. https:// doi.org/10.1016/0098-3004(92)90077-5

Fleischmann M (2019) MOMEPY: urban morphology measuring toolkit. J Open Sour Softw 4(43):1807

Franco-Bedoya O, Ameller D, Costal D, Franch X (2017) Open source software ecosystems: a systematic mapping. Inf Softw Technol 91:160-85

Gaboardi JD, Laura J, Rey S, Wolf LJ, Folch DC, Kang W, Stephens P, Schmidt C (2018) Pysal/Spaghetti. https://github.com/pysal/spaghetti. Accessed 12 Oct 2020

Gancarz M (2003) Linux and the unix philosophy. Digital Press, Newton

Garrard C (2016) Geoprocessing with python. Manning Publications, Shelter Island, NY

Giraud T (2019) Osrm: interface between R and the Open Street Map-based routing service (OSRM). https://github.com/rCarto/osrm. Accessed 18 Oct 2020

Goodman A, Rojas IF, Woodcock J, Aldred R, Berkoff N, Morgan M, Abbas A, Lovelace R (2019) Scenarios of cycling to school in England, and associated health and carbon impacts: application of the 'Propensity to Cycle Tool'. J Transp Health 12:263-78. https://doi.org/10.1016/j.jth.2019.01.008

Grabowicz PA, Ramasco JJ, Moro E, Pujol JM, Eguiluz VM (2012) Social features of online networks: the strength of intermediary ties in online social media. PLoS ONE 7(1):e29358

Graser A (2019) Movingpandas: efficient structures for movement data in python. GIForum 1:54-68

Grinberg M (2018) Flask web development: developing web applications with python. O'Reilly Media Inc, Newton 
Hackl R, Raffler C, Friesenecker M, Kramar H, Kalasek R, Soteropoulos A, Wolf-Eberl S, Posch P, Tomschy R (2019) Promoting active mobility: evidence-based decision-making using statistical models. J Transp Geogr 80:102541. https://doi.org/10.1016/j.jtrangeo.2019.102541

Hadfield P, Cook N (2019) Financing the low-carbon city: can local government leverage public finance to facilitate equitable decarbonisation? Urban Policy Res 37(1):13-29. https://doi.org/10.1080/08111 146.2017.1421532

Hall M, Willumsen LG, Van Vliet D (1980) SATURNa simulation-assignment model for the evaluation of traffic management schemes. Traff Eng Control 21(4)

Harrison RM, Hester RE (2017) Environmental impacts of road vehicles: past, present and future. Royal Society of Chemistry, London

Hickman R, Ashiru O, Banister D (2011) Transitions to low carbon transport futures: strategic conversations from London and Delhi. J Transp Geogr Spec Sect Altern Travel Futures 19(6):1553-62. https://doi.org/10.1016/j.jtrangeo.2011.03.013

Hildebrand C, Hörtin S (2014) A comparative study between emme and visum with respect to public transport assignment. http://urn.kb.se/resolve?urn=urn:nbn:se:liu:diva-112783. Accessed 18 Oct 2020

Hollander Y (2016) Transport modelling for a complete beginner. CTthink! ISBN: 978-0-9956624-1-4

Horni A, Nagel K, Axhausen KW (2016) The multi-agent transport simulation MATSim. Ubiquity Press, London

Hull A (2008) Policy integration: What will it take to achieve more sustainable transport solutions in cities? Transp Policy New Dev Urban Transp Plan 15(2):94-103. https://doi.org/10.1016/j.tranp ol.2007.10.004

Iacono M, Krizek KJ, El-Geneidy A (2010) Measuring non-motorized accessibility: issues, alternatives, and execution. J Transp Geogr 18(1):133-40. https://doi.org/10.1016/j.jtrangeo.2009.02.002

Jäppinen S, Toivonen T, Salonen M (2013) Modelling the potential effect of shared bicycles on public transport travel times in greater Helsinki: an open data approach. Appl Geogr 43:13-24

Johansson C, Lövenheim B, Schantz P, Wahlgren L, Almström P, Markstedt A, Strömgren M, Forsberg B, Sommar JN (2017) Impacts on air pollution and health by changing commuting from car to bicycle. Sci Total Environ 584-585:55-63. https://doi.org/10.1016/j.scitotenv.2017.01.145

Joo R, Boone ME, Clay TA, Patrick SC, Clusella-Trullas S, Basille M (2020) Navigating through the R packages for movement. J Anim Ecol 89(1):248-67. https://doi.org/10.1111/1365-2656.13116

Kampa M, Castanas E (2008) Human health effects of air pollution. Environ Pollut 151(2):362-67. https://doi.org/10.1016/j.envpol.2007.06.012

Kilian J, Kitazawa M (2018) The emerging risk of exposure to air pollution on cognitive decline and Alzheimer's disease - Evidence from epidemiological and animal studies. Biomed J 41:141162. https://doi.org/10.1016/j.bj.2018.06.001

Klosterman RE (1999) The what if? Collaborative planning support system. Environ Plan B Plan Des 26(3):393-408. https://doi.org/10.1068/b260393

Knuth DE (1997) The art of computer programming: volume 1: fundamental algorithms. AddisonWesley Professional, Boston

Kotusevski G, Hawick KA (2009) A review of traffic simulation software. Res Lett Inf Math Sci $13: 35-54$

Larsen J, Patterson Z, El-Geneidy A (2013) Build it. But where? The use of geographic information systems in identifying locations for new cycling Infrastructure. Int J Sustain Transp 7(4):299-317

Legacy C (2016) Is there a crisis of participatory planning? Plann Theory 16(4):425-42. https://doi. org/10.1177/1473095216667433

Levinson D (2012) Network structure and city size. PLoS ONE 7(1):e29721. https://doi.org/10.1371/ journal.pone.0029721

Liao S, Zhou L, Di X, Yuan B, Xiong J (2018) Large-scale short-term urban taxi demand forecasting using deep learning. In: 2018 23rd Asia and South Pacific design automation conference (ASPDAC). IEEE, pp 428-433

Lindsey G, Steve H, Xize W, Junzhou C (2013) The Minnesota bicycle and pedestrian counting initiative: methodologies for non-motorized traffic monitoring. Minnesota Department of Transportation, Minnesota

Litman T (2007) Developing indicators for comprehensive and sustainable transport planning. Transp Res Rec J Transp Res Board 2017:10-15. https://doi.org/10.3141/2017-02 
Löfgren S, Nilsson KL, Johansson CM (2018) Considering landscape in strategic transport planning. Transp Res Part D Transp Environ 65:396-408. https://doi.org/10.1016/j.trd.2018.09.001

Loidl M, Wallentin G, Cyganski R, Graser A, Scholz J, Haslauer E (2016) GIS and transport modelingstrengthening the spatial perspective. ISPRS Int J Geo-Inf 5(6):84. https://doi.org/10.3390/ ijgi5060084

Lopez PA, Behrisch M, Bieker-Walz L, Erdmann J, Flötteröd Y-P, Hilbrich R, Lücken L, Rummel J, Wagner P, WieBner E (2018) Microscopic traffic simulation using sumo. In: 2018 21st international conference on intelligent transportation systems (ITSC). IEEE, pp 2575-2582

Lovelace R, Ellison R (2018) Stplanr: a package for transport planning. R J 10(2):7-23. https://doi. org/10.32614/RJ-2018-053

Lovelace R, Birkin M, Cross P, Clarke M (2016) From big noise to big data: toward the verification of large data sets for understanding regional retail flows. Geogr Anal 48(1):59-81. https://doi. org/10.1111/gean.12081

Lovelace R, Goodman A, Aldred R, Berkoff N, Abbas A, Woodcock J (2017) The propensity to cycle tool: an open source online system for sustainable transport planning. J Trans Land Use. https:// doi.org/10.5198/jtlu.2016.862

Lovelace R, Nowosad J, Muenchow J (2019) Geocomputation with R. CRC Press, Boca Raton

Lovelace R, Parkin J, Cohen T (2020) Open access transport models: a leverage point in sustainable transport planning. Transp Policy 97:47-54. https://doi.org/10.1016/j.tranpol.2020.06.015

Luxen D, Vetter C (2011) Real-time routing with openstreetmap data. In: Proceedings of the 19th ACM SIGSPATIAL international conference on advances in geographic information systems, pp 513-516

Majic I, Pafka E (2019) AwaP-ICAn open-source GIS tool for measuring walkable access. Urban Sci $3(2): 48$

Miller HJ (1999) Potential contributions of spatial analysis to geographic information systems for transportation (GIS-T). Geogr Anal 31(4):373-99. https://doi.org/10.1111/j.1538-4632.1999. tb00991.x

Moeckel R, Garcia CL, Chou ATM, Okrah MB (2018) Trends in integrated land use/transport modeling: an evaluation of the state of the art. J Transp Land Use. https://doi.org/10.5198/ jtlu.2018.1205

Monbiot G (2017) Out of the wreckage: a new politics for an age of crisis. Verso Books, Brooklyn, NY

Morgan M, Lovelace R (2020) Travel flow aggregation: nationally scalable methods for interactive and online visualisation of transport behaviour at the road network level. Environ Plan B Plan Des. https://doi.org/10.1177/2399808320942779

Morgan M, Young M, Lovelace R, Hama L (2019) OpenTripPlanner for R. J Open Sour Softw 4(44):1926. https://doi.org/10.21105/joss.01926

Moriarty P, Honnery D (2008) The prospects for global green car mobility. J Clean Prod 16(16):171726. https://doi.org/10.1016/j.jclepro.2007.10.025

Morrison R (2018) Energy system modeling: public transparency, scientific reproducibility, and open development. Energy Strat Rev 20:49-63

Neteler M, Mitasova H (2008) Open source GIS: a GRASS GIS approach, 3rd edn. Springer, New York, NY

O’Flaherty C, Bell MGH (1997) Transport planning and traffic engineering. Elsevier, Amsterdam

Padgham M (2019) Dodgr: an R package for network flow aggregation. Trans Find. https://doi. org/10.32866/6945

Pappalardo L, Barlacchi G, Simini F, Pellungrini R (2019) Scikit-mobility: an open-source python library for human mobility analysis and simulation. arXiv:1907.07062 [physics]

Parkin J (2018) Designing for cycle traffic: international principles and practice. ICE Publishing, London

Pensa S, Masala E, Lami IM (2013) Supporting planning processes by the use of dynamic visualisation. In: Geertman S, Toppen F, Stillwell J (eds) Planning support systems for sustainable urban development. Lecture Notes in Geoinformation and Cartography. Springer-Verlag, Berlin Heidelberg, pp 451-67. https://doi.org/10.1007/978-3-642-37533-0

Peters MA (2020) Citizen science and ecological democracy in the global science regime: the need for openness and participation. Educ Philos Theory 52(3):221-26. https://doi.org/10.1080/00131 857.2019.1584148 
Pettit CJ, Barton J, Goldie X, Sinnott R, Stimson R, Kvan T (2014) The Australian urban intelligence network supporting smart cities. In: Geertma S, Stillwell J, Ferreira J, Goodspeed J (eds) Smart cities and planning support systems. Springer, Berlin

Pucher J, Buehler R (2008) Making cycling irresistible: lessons from the Netherlands, Denmark and Germany. Transp Rev 28:495-528

Riggs WW, Boswell MR, Ross R (2016) Streetplan: hacking streetmix for community-based outreach on the future of streets. Focus 13(1):14

Rodrigue J-P, Comtois C, Slack B (2013) Geography of transport systems, 3rd edn. Routledge, London

Sallis JF, Bull F, Burdett R, Frank LD, Griffiths P, Giles-Corti B, Stevenson M (2016) Use of science to guide city planning policy and practice: how to achieve healthy and sustainable future cities. The Lancet 388(10062):2936-47

Salter JD, Campbell C, Journeay M, Sheppard SRJ (2009) The digital workshop: exploring the use of interactive and immersive visualisation tools in participatory planning. J Environ Manag Collab GIS Spatial Decis Support Vis 90(6):2090-2101. https://doi.org/10.1016/j.jenvm an.2007.08.023

Shamal A.-D, Kamw F, Zhao Y, Ye X, Yang J, Jamonnak S (2019) An open source trajAnalytics software for modeling, transformation and visualization of urban trajectory data. In: 2019 IEEE Intelligent Transportation Systems Conference (ITSC). IEEE, pp 150-155

Schmutz B, Sidib'e M (2019) Frictional labour mobility. Rev Econ Stud 86(4):1779-1826. https://doi. org/10.1093/restud/rdy056

Sherman G (2008) Desktop GIS: mapping the planet with open source tools. Pragmatic Bookshelf, Raleigh

Singleton A, Arribas-Bel D (2019) Geographic data science. Geogr Anal 51:1-15. https://doi. org/10.1111/gean.12194

te Brömmelstroet M, Bertolini L (2008) Developing land use and transport PSS: meaningful information through a dialogue between modelers and planners. Transp Policy 15(4):251-59. https:// doi.org/10.1016/j.tranpol.2008.06.001

Timms P, Tight M, Watling D (2014) Imagineering mobility: constructing utopias for future urban transport. Environ Plann 46(1):78-93. https://doi.org/10.1068/a45669

Tornberg P, Odhage J (2018) Making transport planning more collaborative? The case of strategic choice of measures in Swedish transport planning. Transp Res Part A Policy Pract 118:416-29. https://doi.org/10.1016/j.tra.2018.09.020

Transport Systems Catapult (2015) The Transport Data Revolution. Government, Transport Systems Catapult

Tribby CP, Zandbergen PA (2012) High-resolution spatio-temporal modeling of public transit accessibility. Appl Geogr 34:345-55. https://doi.org/10.1016/j.apgeog.2011.12.008

Vandenbulcke G, Thomas I, de Geus B, Degraeuwe B, Torfs R, Meeusen R, Panis LI (2009) Mapping bicycle use and the risk of accidents for commuters who cycle to work in Belgium. Transp Policy 16(2):77-87. https://doi.org/10.1016/j.tranpol.2009.03.004

Waddell P (2002) UrbanSim: modeling urban development for land use, transportation, and environmental planning. J Am Plan Assoc 68:297-314

Wickham H (2020) Mastering Shiny. https://mastering-shiny.org/. Accessed 29 Oct 2020 (in press)

World Health Organization (2018) Global status report on road safety 2018. S.1

Xie F, Levinson D (2011) Evolving transportation networks transportation research. Economics and policy. Springer, New York

Publisher's Note Springer Nature remains neutral with regard to jurisdictional claims in published maps and institutional affiliations. 